\title{
Kualitas Semen Produksi UPTD Bengkulu dan Tingkat Keberhasilan Inseminasi pada Sapi Bali dan Peranakan Simental di Bengkulu
}

\author{
Semen Quality Produced by UPTD Bengkulu and Success Rate of Insemination on Bali Cattle \\ and Simental Cross in Bengkulu
}

T. Suteky, Sutriyono, Dwatmadji dan M. I. Sholihin

Jurusan Peternakan Fakultas Pertanian-Universitas Bengkulu

J1. WR Supratman Kandang limun Bengkulu 38371 Telp: 081539325865

Email: Tatiksuteky.2008@yahoo.com

\begin{abstract}
The purpose of this study was to evaluate the performance reproduction of Bali and Simmental cattle to artificially inseminate with frozen semen produced by Regional Technical Implementation Unit of Artificial Insemination (UPTD-IB) Bengkulu province. Data collection was performed using a questionnaire based on interviews. Primary data were collected from 30 respondents (farmers with a total of 163 cattle), data collected were age, education, duration of maintaining cattle, livelihoods and the principal amount of cattle ownership. Secondary data were obtained from Artificial card. Parameters observed were in the level of success based Services per conception (S / C) and Non-Return Rate (NRR). This study showed the semen volume (5,4-7 ml), colour (cream) pH 7, sperm concentration 650-700 juta $\mathrm{ml}^{-}$, , percentage progressive motile sperm al 65-70\%. Result also showed that an average NRR 77-84\% and S/C 1.1-1.2 on Bali cattle; whereas S/C and NRR of Simental were 1.8 and $46 \%$. The conclusion that the success rate of Bali cattle better than the Simental cattle in the province of Bengkulu based Services per conception (S /C) and Non-Return Rate (NRR).
\end{abstract}

Key words: Semen quality, Bali cattle, S/C, and NRR

\begin{abstract}
ABSTRAK
Tujuan penelitian ini adalah untuk mengevaluasi kualitas semen yang di produksi Unit Pelaksana Teknis Daerah Inseminasi Buatan (UPTD IB) Provinsi Bengkulu dan hasil Inseminasi Buatannya. Pemeriksaan semen dilakukan di laboratorium UPTD-IB Bengkulu, untuk mengevaluasi keberhasilan IB materi yang dipergunakan adalah 163 ekor sapi yang di IB dengan semen beku produksi UPTD-IB, sapi tersebut milik 30 peternak tersebar di 3 wilayah kotamadia Bengkulu, Kabupaten Bengkulu Utara dan Bengkulu Tengah. Data sekunder diperoleh dari kartu IB di Dinas Peternakan dan inseminator meliputi karakteristik peternak meliputi umur, pendidikan, lama memelihara sapi potong, mata pencarian pokok dan jumlah kepemilikan sapi. Paramater yang diamati 1. Kualitas semen yang meliputi volume, warna, $\mathrm{pH}$, motilitas dan konsentrasi 2. Performan reproduksi Service per conception $(S / C)$ dan Non Return Rate (NRR). Hasil penelitian menunjukkan kualitas semen segar telah memenuhi standar dengan volume 5,4-7 ml, warna putih-kream, $\mathrm{pH}$ 7, gerakan masa skor positif 2, spermatozoa motil 65-70\%, konsentrasi 650-700 juta $\mathrm{ml}^{-1}$. Hasil penelitian juga menunjukkan S/C sapi Bali tidak berbeda nyata,rata-rata NRR dan S/C sapi Bali di Kabupaten Bengkulu Tengah 77\%, S/C 1,2, sapi Bali di Kotamadia Bengkulu 84\%, S/C 1,1, sapi Bali di Kabupaten Bengkulu Utara 77\%, S/C 1,2 sedangkan sapi peranakan Simental 46\%, SC 1,8. Kesimpulan dari penelitian bahwa tingkat keberhasilan sapi Bali lebih baik dari pada sapi Peranakan Simental.
\end{abstract}

Kata kunci : kualitas semen, sapi Bali, S/C dan NNR

\section{PENDAHULUAN}

Upaya pemerintah Indonesia dalam penyediaan bibit sapi, sudah diinisiasi tahun 1975 dengan mendirikan Balai Inseminasi Buatan (BIB) pertama di Indonesia yang berlokasi di Lembang Bandung dan diresmikan oleh Menteri 
Pertanian RI dan Wakil Perdana Menteri Selandia Baru pada tanggal 3 April 1976. Pendirian BIB Lembang untuk memenuhi kebutuhan pelaksanaan Inseminasi Buatan (IB) di Indonesia, agar tidak tergantung dengan semen beku impor. Tugas pokok BIB Lembang yaitu melaksanakan produksi dan pemasaran semen beku benih unggul sapi potong dan perah serta pengembangan IB. Dengan meningkatnya kebutuhan akan semen beku, pemerintah menegaskan kembali pentingnya penyediaan bibit/bakalan yang mudah dijangkau di seluruh Indonesia. Upaya tersebut jelas terdokumentasi dalam UU No. 18 tahun 2009, Pasal 13 ayat (2) yakni: Pemerintah berkewajiban untuk melakukan pengembangan usaha pembenihan dan/atau pembibitan dengan mengutamakan produksi dalam negeri dan kemampuan ekonomi kerakyatan.

Gubernur Bengkulu melalui Peraturan Gubernur No. 22 Tahun 2008 tentang Pembentukan Organisasi, uraian Tugas Pokok dan Fungsi UPT pada Dinas dan Badan Provinsi Bengkulu mendirikan Unit Pelaksana Teknis Daerah Inseminasi Buatan Dinas Peternakan dan Kesehatan Hewan Provinsi Bengkulu. Keberadaan UPTD IB ini diharapkan dapat menjawab tantangan dalam pembangunan daerah melalui peningkatan produksi dan kualitas ternak, terutama ternak sapi. Sejalan dengan kebijakan pemerintah untuk mengembangkan teknologi di daerah dan untuk memenuhi permintaan masyarakat akan bibit ternak, maka sejak tahun 2010 UPTD IB telah memproduksi semen cair dan pada tahun 2013 mulai mencoba memproduksi semen beku, di tahun 2014 produksi semen bekunya mulai di realease di dua kabutapen yakni Bengkulu Tengah dan Utara. diharapkan dapat digunakan untuk mendukung program pemerintah pusat dalam swasembada daging sapi.

Visi UPTD IB Provinsi Bengkulu adalah menjadikan produsen semen cair dan beku yang tersertifikasi pada tahun 2015 untuk memenuhi kebutuhan ternak di Provinsi Bengkulu dan sekitarnya, misi Unit Pelaksana Teknis Daerah Inseminasi Buatan (UPTD IB) Provinsi Bengkulu (a) Memproduksi dan mendistribusikan semen cair dan beku dalam rangka pelayanan kepada masyarakat (b) Menerapkan teknologi inseminasi buatan untuk meningkatkan populasi ternak sapi. Tujuan penelitian ini adalah untuk mengevaluasi kualitas semen produksi UPTD-Bengkulu yang dipergunakan untuk meng inseminasi buatan sapi Bali dan Simental di Bengkulu.

\section{MATERI DAN METODE}

Penelitian ini dilaksanakan, di Unit Pelaksana Teknis Daerah Inseminasi Buatan Provinsi Bengkulu dan peternak di Kota Bengkulu, Bengkulu Utara dan Bengkulu Tengah. Peralatan yang digunakan dalam penelitian ini antara lain alat tulis, daftar pertanyaan kuisioner, termometer serta peralatan penunjang lainnya. Lokasi dipilih secara purposif (ditentukan) yaitu daerah yang ada program inseminasi buatan (IB) dengan menggunakan semen produksi Unit Pelaksana Teknis Daerah Inseminasi Buatan (UPTD IB) Provinsi Bengkulu 
yaitu di Kabupaten Bengkulu Tengah, Kota Bengkulu dan Bengkulu Utara.

Data yang diperoleh bersumber dari Unit Pelaksana Teknis Daerah Inseminasi Buatan (UPTD IB) Provinsi Bengkulu yang mencakup keberadaan inseminator dan penyebaran straw. Pengumpulan data dilakukan menggunakan metode wawancara dengan alat bantu kuisioner.
Data sekunder diperoleh dari kartu IB di Dinas Peternakan dan inseminator.

Hasil evaluasi semen segar didapatkan dari data sekunder di UPTD IB, evaluasi semen segar selalu dilakukan setelah penampungan. Pemeriksaan makroskopis meliputi volume, warna, $\mathrm{pH}$ dan konsistensi. Pemeriksaan mikroskopis spermatozoa semen meliputi konsentrasi, motilitas masa dan individu.

\section{HASIL DAN PEMBAHASAN}

\section{Kualitas Semen Segar UPTD IB Bengkulu.}

Tabel 1. Kualitas semen segar UPTD IB Bengkulu

\begin{tabular}{llllllll}
\hline Bangsa & No Batch & Warna & $\begin{array}{l}\text { Volume } \\
(\mathrm{ml})\end{array}$ & Gerak & $\begin{array}{l}\text { Motilitas } \\
(\%)\end{array}$ & $\begin{array}{l}\text { Konsentrasi } \\
(\text { Juta })\end{array}$ & $\mathrm{pH}$ \\
\hline Bali & $20141110 / 1002$ & Putih & 5,0 & ++ & 65 & 650 & 7 \\
Bali & $20141110 / 1002$ & Putih & 5,4 & ++ & 70 & 700 & 7 \\
Simental & $20140910 / 2001$ & Krem & 7,0 & ++ & 70 & 900 & 7 \\
\hline
\end{tabular}

Hasil pemeriksaan semen segar dapat dilihat pada Tabel 1 diatas, volume berkisar antara 5-5,4 ml (semen sapi Bali), dan $7 \mathrm{ml}$ semen sapi Simental. Motilitas sperma adalah jumlah pergerakan spermatozoa hidup dan bergerak maju/progresif yang nilainya berkisar antara $0-100 \%$ (SNI 01-4869.1-2005). Motilitas sperma segar produksi Unit Pelaksana Teknis Daerah Inseminasi Buatan (UPTD IB) Provinsi Bengkulu cukup baik dan layak untuk diproses selanjutnya dengan kisaran 65-70\%. Pada umumnya dan yang terbaik adalah pergerakan progresif atau gerakan aktif maju kedepan. Selanjutnya ditambahkan oleh Hafez (2000), bahwa persentase hidup spermatozoa harus lebih dari $50 \%$ untuk bisadiproses menjadi semen beku.

Konsentrasi yang baik dan layak untuk diproses menjadi semen beku adalah 800-2000 juta/ml, sementara konsentrasi semen produksi Unit Pelaksana Teknis Derah Inseminasi Buatan (UPTD-IB) berkisar antara 650-900 juta/ml. Hasil tersebut menunjukan bahwa konsentrasi sperma masih layak untuk dilakukan proses selanjutnya. Perbedaan konsentrasi spermatozoa antar pejantan diduga disebabkankarena kualitas genetik pada masing-masing pejantan (Situmorang, 2002). Konsentrasi dan persentase 
spermatozoa motil dipengaruhi oleh umur pejantan dan mempunyai kecenderungan untuk meningkat seiring dengan meningkatnya umur sampai 22 bulan (Mathevon, et al., 1998).

\section{Jumlah Ternak}

Jumlah ternak pada penelitian ini sebanyak 163 ekor, tersebar di 3 Kabupaten yakni Bengkulu Tengah, Kotamadya Bengkulu dan Bengkulu Utara. Bangsa ternak yang dominan dipelihara oleh peternak adalah sapi Bali, sapi Bali merupakan sapi yang relatif mudah dalam pemeliharaanya karena dapat memanfaatkan limbah dan rumput lapangan sebagai pakan mudah beradaptasi dengan lingkungan (Lindell, 2013), dan sudah mulai di distribusikan ke seluruh Indonesia sejak tahun 1912 (Bangsa sapi yang sedang digalakan adalah Simental, sedangkan jumlah responden sebanyak 30 orang.

Tabel 2. Jumlah ternak yang di IB dengan semen produksi UPRD-Bengkulu

\begin{tabular}{llll}
\hline No & Kabupaten & Bangsa Ternak & Jumlah Ternak \\
\hline 1 & Bengkulu Tengah & Bali & 18 \\
2 & Kotamadya Bengkulu & Bali & 33 \\
3 & Bengkulu Utara & Bali & 62 \\
4 & Bengkulu Utara & Simental & 50 \\
\hline
\end{tabular}

\section{Karakteristik Peternak}

Karakteristik peternak merupakan hal yang penting untuk dievaluasi karena berhubungan langsung dengan kemampuan pemeliharaan ternaknya. Karakteristik peternak y a $\mathrm{g}$ meliputi umur peternak, tingkat pendidikan, motivasi beternak, pengalaman beternak dan jumlah kepemilikan ternak sapi dapat dilihat pada Grafik dan Tabel berikut.

Hasil penelitian menunjukkan umurnya peternak responden masih dalam usia produktif yakni $88 \%$ berusia 25-49 tahun sedanga $12 \%$ berusia antara 50-60 tahun. artinya pada usia tersebut aktif dalam menjalankan usahanya baik bercocok tanam maupun beternak. Menurut BPS (2010) interval umur produktif di Indonesia yaitu 15-64 tahun. Tingkat perekonomian terkait dengan tingkat pendidikan, $56 \%$ responden berpendidikan tamatan SD. Untuk jejang yang lebih tinggi sampai SMP-SMA sebanyak $32 \%$ sedangkan untuk jenjang Sarjana hanya $12 \%$, Tingkat pendidikan mempengaruhi peternak dalam adaptasi dan inovasi dalam beternak (Mulyawati et al., 2016) dengan demikain tingkat pendidikan peternak akan mempengaruhi pola berpikir, kemampuan belajar, dan taraf intelektual. 
Tabel 3. Karakteristik peternak, pengalaman beternak dan pekerjaan pokok

\begin{tabular}{lll}
\hline No. & Uraian & Peternak \\
\hline 1 & Tingkat Pendidikan (\%) & \\
& SD & 56 \\
& SMP-SMA & 32 \\
& Sarjana & 12 \\
\hline 2 & Pengalaman beternak (\%) & 18 \\
& 1-3 Tahun & 20 \\
& 3-6 Tahun & 62 \\
\hline Lebih 7 Tahun & 60 \\
\hline 3 & Pekerjaan pokok (\%) & 12 \\
& Bertani & 28 \\
\hline & PNS & $3,76 \pm 0,9$ \\
\hline 4 & Lain-lain & Kepemilikan ternak
\end{tabular}

Pengalaman beternak responden merupakan gambaran lamanya berusaha dalam usaha peternakan. Beternak sapi pada umumnya bersifat turun temurun yang diwariskan dari orang tuanya atau belajar dari lingkungan sekitarnya. Pengalaman responden selama 1-3 tahun sebanyak 18\%, pengalaman tersebut tergolong baru dimana peternak belum memiliki pengalaman maka ketrampilan dan sikap terhadap usaha ternak yang dikelolanya belum memadai. Sebanyak $20 \%$ responden mengaku berpengalaman selama 3-6 tahun, artinya peternak sudah memiliki pengalaman dan keterampilan dalam memelihara ternaknya. Sementara $62 \%$ peternak sudah cukup berpengalaman selama lebih dari 7 tahun dimana semakin lama pengalaman beternak maka produktivitas yang dihasilkannya pun semakin bertambah, karena semakin tinggi tingkat pengalaman beternak, maka ketrampilan dan sikap terhadap usaha ternak yang dikelolanya akan semakin baik (Kusnadi et al., 1983). Mulyawati et al.
(2016) menemukan tingkat pendidikan berkorelasi secara signifikan terhadap perilaku beternak.

Persentase responden yang bekerja sebagai petani/peternak adalah sebesar $60 \%$, sedangkan sisa nya pekerjaan beternak sapi merupakan sambilan sebagai pegawai negeri sipil atau pun pekerjaan lain seperti tukang dan berdagang. Pada Tabel 2 juga terlihat bahwa secara umum rataan kepemilikan ternak sebanyak 3,76 \pm 0,9 , hal ini menunjukkan bahwa peternak di daerah penelitian yang menggunakan semen IB produksi lokal UPTD-Bengkulu tergolong peternak dengan skala kecil. Non Return Rate adalah persentase betina yang tidak minta kawin kembali atau tidak mengalami berahi lagi dalam waktu 60-90 hari pasca IB (Toilehere, 1981).

Hasil analisis ragam menunjukkan bahwa tidak ada perbedaan yang nyata $(\mathrm{P}>0,05)$ persentase NRR pada sapi Bali di 3 kabupaten/kotamadia di Bengkulu, yakni antara 77 sampai dengan $84 \%$. 
Tabel 4. Rataan non return rate (NRR) pada sapi Bali dan Peranakan Simental di Provinsi Bengkulu.

\begin{tabular}{lll}
\hline \multicolumn{1}{c}{ Bangsa } & \multicolumn{1}{c}{ Kabupaten } & \multicolumn{1}{c}{ NRR } \\
\hline Bali & Bengulu Tengah & $77 \pm 0,42^{\mathrm{a}}$ \\
Bali & Kota Madya Bengkulu & $84 \pm 0,36^{\mathrm{a}}$ \\
Bali & Bengkulu Utara & $77 \pm 0,42^{\mathrm{a}}$ \\
Simental & Bengkulu Utara & $46 \pm 0,98^{\mathrm{b}}$ \\
\hline
\end{tabular}

Hasil tersebut berada dalam kisaran penelitian Iswoyo et al. (2006) yang menemukan bahwa persentase NRR yang baik adalah $79,53 \pm 18 \%$. Hal ini menunjukkan bahwa kualitas semen beku yang di produksi oleh UPTD- Bengkulu memiliki kualitas yang baik dan sudah memenuhi Standar Nasional Indonesia (SNI) bagi kualitas semen segar yang dapat dipakai untuk inseminasi buatan adalah minimum mengandung 500 juta $\mathrm{sel} / \mathrm{ml}$ ejakulat dan $50 \%$ spermatozoa hidup dan aktif. Jalius (2011), semakin baik kualitas sperma, maka semakin besar keberhasilan inseminasi buatan. berdasarkan. Nilai NRR terbaik sebesar $84 \%$ pada sapi Bali di Kota Bengkulu, hal ini mungkin disebabkan karena dekatnya jarak peternak dengan UPTD-Bengkulu. Yusuf et al. (2015) menemukan bahwa faktor nutrisi sangat mempengaruhi performan reproduksi.

Rendahnya nilai NRR pada sapi Simental dapat disebabkan banyak faktor. Susilawati (2011) berpendapat bahwa munculnya berahi kembali dalam pengamatan NRR selain faktor nutrisi yang kurang, juga dipengaruhi oleh kematian embrio dini atau waktu pelaksanaan IB yang kurang tepat karena informasi yang kurang tepat dari laporan peternak. Ditambahkan oleh Yusran et al. (2001) keberhasilan inseminasi buatan dipengaruhi oleh kualitas straw, ketepatan IB, keterampilan inseminator serta kondisi induk dan pakan yang baik.Pakan yang diberikan relatif sama yaitu dengan pemberian hijauan ad libitum sehingga faktor pakan kurang berpengaruh dalam tingkat NRR, begitu juga dengan inseminator yang ada dilapangan dapat berpengaruh terhadap tingkat keberhasilan NRR.

Pada lokasi penelitian hanya terdapat satu inseminator, sehingga faktor inseminator kurang berpengaruh terhadap nilai NRR. Faktor suhu dan kelembaban diduga sebagai penyebab NRR rendah yang dapat mempengaruhi fisiologi ternak betina. Iskandar (2011) menyatakan bahwa suhu yang nyaman untuk sapi Bos taurus adalah $15^{\circ} \mathrm{C}$ dan kelembapan $80 \%$. Sementara hasil penelitian menunjukan suhu di lingkungan penelitian $\pm 27^{\circ} \mathrm{C}$ sehingga kurang optimal untuk sapi-sapi Bos taurus dan akan berpengaruh terhadap NRR. Pada ternak sub tropis sering mengalami gangguan reproduksi karena tidak bisa beradaptasi pada lingkungan tropis. Hal ini terjadi karena hormon gonadotropin dan steroid tidak dapat dihasilkan secara sempurna sehingga mengakibatkan silent heat. Kemampuan sapi betian untuk bunting pada inseminasi pertama dan tidak mengalami berahi lagi 
sangat dipengaruhi oleh variasi lingkungan (Nuryadi dan Wahjuningsih, 2011).

Service per Conception (S/C) adalah banyaknya perkawinan atau inseminasi buatan yang dilakukan hingga ternak menjadi bunting. Semakin rendah nilai S/C, maka makin tinggi kesuburan ternak betina tersebut (Jainudeen dan Hafez, 2000). Toelihere (1985) menyebutkan bahwa nilai S/C yang normal berkisar antara 1,6 - 2,0. makin rendah nilai $\mathrm{S} / \mathrm{C}$ maka makin tinggi nilai kesuburan hewan betina dalam kelompok tersebut.

Tabel 5. Rataan nilai Servive per conception (S/C) pada sapi Bali dan peranakan Simental di Provinsi Bengkulu

\begin{tabular}{lll}
\hline Bangsa & Kabupaten & S/C \\
\hline Bali & Bengkulu Tengah & $1,2 \pm 0,42^{\mathrm{a}}$ \\
Bali & Kota Bengkulu & $1,1 \pm 0,36^{\mathrm{a}}$ \\
Bali & Bengkulu Utara & $1,2 \pm 0,42^{\mathrm{a}}$ \\
Simental & Bengkulu Utara & $1,8 \pm 0,98^{\mathrm{b}}$ \\
\hline
\end{tabular}

Hasil penelitian menunjukkan bahwa S/C Sapi Bali di 3 kabupaten di Propinsi Bengkulu menunjukkan tidak berbeda nyata $(\mathrm{P}>0,05)$ dengan range antara 1,1-1,2. Hasil ini lebih baik apabila dibandingkan dengan penelitian sebelumnya S/C sapi Bali yang dimanfaatkan sebagai ternak kerja untuk mengangkut tandan buah segar yakni 1,5 (Suteky dan Dwatmadji, 2009) . S/C yang normal antara 1-2 (Devendra et al., 1973; Rasad, 2009). Rata-rata S/C pada sapi Simental 1,8, hasil ini lebih rendah apabila dibandingkan dengan penelitian Ihsan (2011) yang melaporkan bahwa S/C sapi Simental yaitu 1,23-1,35. Faktor yang mempengaruhi $\mathrm{S} / \mathrm{C}$ adalah kombinasi faktor genetik dan pakan dan kesehatan ternak (Kusuma, 2006). Berdasarkan hasil penelitian pakan yang diberikan berupa rumput lapang, rumput gajah dan limbah pertanian antara lain jerami padi.

\section{KESIMPULAN}

Kualitas semen yang diproduksi oleh UPTD-IB Bengkulu telah memenuhi syarat SNI, hasil inseminasi buatan menunjukkan S/C pada sapi Bali 1,1-1,2 sedangkan pada sapi Simental 1,8 , NRR pada sapi Bali $77-84 \%$, sedangkan sapi Simental $46 \%$.

\section{DAFTAR PUSTAKA}

Davendra, C.T.; K.C. Lee, and Pathmasingam. 1973. The productivity of Bali cattle in Malaysia. Agricultural Journal 49: 183-197.

Hafez, E.S.E. 2000. Semen evaluation in reproduction in farm animals. 7 th Edition. Lippincott Wiliams And Wilkins. Maryland, USA.

Ihsan dan Wahjuningsih. 2001. Penampilan Reproduksi Sapi 
Potong di Kabupaten Bojonegoro. Jurnal Tropika. 12 (2) 76-80.

Iskandar. 2011. Performan Reproduksi Sapi PO pada Dataran Rendah dan Dataran Tinggi di Provinsi Jambi. Jurnal Ilmiah Ilmu-Ilmu Peternakan, 14 (1): 51-61.

Iswoyo dan Widiyaningrum, P. 2006. Performans reproduksi sapi Peranakan Simmental (PSM) hasil inseminasi buatan di Kabupaten Sukoharjo Jawa Tengah. Jurnal Ilmiah Ilmu-Ilmu Peternakan. 11 (3): 128 .

Jainudeen, M.R. and Hafez, E.S.E. 2000. Cattle And Buffalo in Reproduction In Farm Animals. $7^{\text {th }}$ Edition. Edited by Hafez E. S. E. Lippincott Williams and Wilkins. Maryland. USA..

Jalius. 2011. Hubungan Motilitas Progresif dan Keutuhan Membran Sperma dalam Semen Beku Sapi Bali dengan Keberhasilan Inseminasi. Agribisnis Peternakan. Universitas Jambi, Jambi.

Lindell, I.C. 2013. Phenotyping of Bali cattle and interviewing farmers in Indonesia - a minor field study. Bachelor Thesis, Faculty of Veterinary Medicine and Animal Science. Swedish University of Agricultural Sciences, Swedia.

Mathevon, M., M. Buhr and J. C. M. Dekkers. 1998. Environmental,
Management and Genetic Factors Affecting Semen Production in Holstein Bulls. JournalDairy Science 81 :3321-3330.

Mulyawati, I.M., D. Mardiningsih, dan S Satmoko. 2016. Pengaruh Umur, Pendidikan, Pengalaman dan Jumlah Ternak Peternak Kambing terhadap Perilaku Sapta Usaha Beternak Kambing di Desa Wonosari Kecamatan Patebon. Agromedia 34 (1):85-90.

Nuryadi dan S. Wahjuningsih. 2011. Penampilan Reproduksi Sapi Peranakan Ongole dan Peranakan Limousin di Kabupaten Malang. Jurnal Ternak Tropika, 12 (1): 7681.

Rasad, S.D. 2009. Evaluasi Penampilan Reproduksi Sapi Perah (Studi Kasus di Perusahaan Peternakan Sapi Perah KUD Sinarjaya). Jurnal Agripet, 9 (1) : 43-49.

Situmorang, P. 2002. The Effects of Inclusion of Exogenous Phospolipid In Tris- Diluent Containing A Different Level of Egg Yolk on the Viability of Bull Spermatozoa. Pusat Penelitian dan Pengembangan Peternakan dan Badan Penelitian dan Pengembangan Pertanian, Bogor 7 (3) : 131-187

Sutarno dan S D Setyawan. 2016. The diversity of local cattle in Indonesia and the efforts to 
develop superior indigenous cattle breeds. Biodiversitas 11 (1): 275295.

Suteky, T. and Dwatmadji. 2009. The effect of work on reproductive performance of Bali cattle under oil palm plantation (Proceeding The first International Seminar on Animal Industry -IPB, Bogor)

Susilawati, T. 2011. Tingkat Keberhasilan Inseminasi Buatan dengan Kualitas dan Deposisi Semen yang Berbeda pada Sapi Peranakan Ongole. J. Ternak Tropika 12 (2) : 15-24.

Undang-Undang Republik Indonesia Nomor 18 tahun 2009 tentang Peternakan dan Kesehatan Hewan.
Yusran, M.A., L. Affandhy dan Suyamto. 2001. Pengkajian Keragaan, Permasalahan dan alternatif solusi program IB sapi potong di Jawa Timur. Pros. Seminar Nasional Teknologi Peternakan dan Veteriner 2001. Puslitbang . Peternakan . Bogor, hal . 155-167.

Yusuf M, D P Rahardja dan AL Toleng . 2015. Prospect of Nutrition InUtero on Improvement of Reproductive Performance in Bali Cows Kept Under Smallholder Farms. Journal of Advanced Agricultural Technologies . 2 (2): 151-155 